\section{Acknowledgements}

We thank all the master trainers, interviewers, senior trainees and consultant psychiatrists (Department of Psychiatry, Military Hospital, Rawalpindi) for their substantial contribution and all those earthquake survivors for their invaluable participation in this pilot study. We also thank Professor Kessler (Co-director of the WHO World Mental Health Survey Initiative) and Dr Basoglu for their assistance in relation to the CIDI-TM and SITSES.

\section{References}

Alexander, D. A. (2005) Early mental health intervention after disasters. Advances in Psychiatric Treatment, 11, 12-18.

Basoglu, M., Salcioglu, E., Livanou, M., et al (2001) A study of the validity of a screening instrument for traumatic stress in earthquake survivors in Turkey. Journal of Traumatic Stress, 14, 491-509.

Basoglu, M., Salcioglu, E. \& Livanou, M. (2002) Traumatic stress responses in earthquake survivors in Turkey. Journal of Traumatic Stress, $15,269-276$

Blake, D. D., Weathers, F. W., Nagy, L., et al (1990) A clinician rating scale for assessing current and lifetime PTSD: the CAPS-1. Behavior Therapist, 13, 187-188.
First, M. B., Spitzer, R. L., Gibbon, M., et al (1996) Structured Clinical Interview for DSM-IV Axis I Disorders - Non-patient Edition (SCIP-I/NP, Version 2). New York State Psychiatric Institute, Biometrics Research Department.

Ghodse, H. \& Galea, S. (2006) Tsunami: understanding mental health consequences and the unprecedented response. International Review of Psychiatry, 18, 289-297.

Karim, S., Saeed, K., Rana, M. H., et al (2004) Pakistan mental health country profile. International Review of Psychiatry, 16, 83-92.

Khan, M. M. (2006) Earthquake 2005: challenges for Pakistani psychiatry. International Psychiatry, 3, 21-23.

Klein, S. \& Alexander, D. A. (2006) Epidemiology and presentation of post-traumatic disorders. Psychiatry, 5, 225-227.

Klein, S. \& Alexander, D. A. (2007) Post-disaster research issues. In The Day the Mountains Moved: Earthquake in Pakistan (ed. U. Niaz), pp. 233-263. SAMA Editorial and Publishing Services.

Mirza, I. \& Jenkins, R. (2004) Risk factors, prevalence, and treatment of anxiety and depressive disorders in Pakistan: systematic review. BMJ, 328, 794.

Rana, M. H., Ali, S., Yusufi, B., et al (2006) National Plan of Action for Mental Health and Psychosocial Relief of Earthquake Survivors - emergency phase. Pakistan Armed Forces Medical Journal, 56, 402-411.

van Ommeren, M., Saxena, S. \& Saraceno, B. (2005) Aid after disasters. BMJ, 330, 1160-1161.

\title{
Traditional health practitioners and mental health in Kenya
}

\author{
Marx Okonji, ${ }^{1}$ Frank Njenga, ${ }^{2}$ David Kiima, ${ }^{3}$ James Ayuyo, ${ }^{4}$ Pius Kigamwa,, \\ Ajit Shah ${ }^{6}$ and Rachel Jenkins
}

${ }^{1}$ Consultant Psychiatrist, Chiromo Lane Medical Centre, Nairobi; ${ }^{2}$ Consultant Psychiatrist, Chiromo Lane Medical Centre, Nairobi; ${ }^{3}$ Director of Mental Health, Ministry of Health, Afya House, Nairobi, Kenya; ${ }^{4}$ Mildmay International, Kisumu, Kenya; ${ }^{5}$ Lecturer, University of Nairobi School of Medicine, Nairobi, Kenya; ${ }^{6}$ Professor of Ageing, Ethnicity and Mental Health, Institute for Philosophy, Diversity and

Mental Health, University of Central Lancashire, Preston, UK;

7Director of the WHO Collaborating Centre, Institute of Psychiatry, De Crespigny Park, London SE5 8AF, UK, email rachel@olan.org

hep

he prevalence of psychiatric morbidity among rural and urban Kenyan primary care attenders has been reported to be as high as 63\% (Ndetei \& Muhangi, 1979; Dhapdale \& Ellison, 1983; Dhapdale et al, 1989; Sebit, 1996). For its population of 32 million, Kenya has only 16 psychiatrists and 200-300 psychiatric nurses, but there are just over 2000 primary healthcare centres, staffed by general nurses and clinical officers, and the main burden for assessing and caring for people with mental disorders falls upon members of the primary care teams. However, mental disorders are poorly recognised (Dhapdale \& Ellison, 1983) and inadequately treated in primary care (Muluka \& Dhapdale, 1986). Moreover, Kenyan primary care workers often lack training in mental health (Dhapdale et al, 1989; see also Ndetei, this issue, p. 31).

In contrast to this picture of poor recognition and treatment of mental disorders in primary care, people with mental disorders commonly consult traditional health practitioners (THPs) in African countries, including South Africa (Zabow, 2007), Nigeria (Olugbile et al, 2007), Tanzania (Ngoma et al, 2003) and Kenya (Ndetei, 2007). Around 50\% of Kenyans who consult THPs may have psychiatric morbidity (Ndetei, 2007) and many use both modern medical services and
THPs simultaneously (Odejide et al, 1978; Ndetei, 2007). In neighbouring Tanzania, the prevalence of common mental disorders among those consulting THPs is high (Ngoma et al, 2003), reflecting the failure of primary care services to detect and treat these disorders adequately. Patients may go to hospitals to seek a cure for their illness, and go to THPs to seek both cure and explanation (Otsyula, 1973), particularly if they are not satisfied with modern medical services (Katz \& Kimani, 1982). Therefore, this paper reports a qualitative study to examine the views of THPs in Kenya pertaining to the nature, aetiology, symptoms and classification of mental illness, as well as treatment approaches, in order to establish whether there is an adequate shared conceptual basis for further dialogue and liaison.

\section{Methods}

\section{Sample}

The sample frame was all 70 THPs either registered with $(n=47)$ or otherwise known to $(n=23)$ Kisumu District Cultural and Social Services Office as practising in the Maseno Division, a poor rural area of 50000 population. All 70 THPs 
Box 1 Issues covered in the focus groups

-What diseases are treated by traditional healers?

- How are mental illnesses treated by traditional healers?

- What happens in a consultation?

- How is abdominal pain treated by traditional healers?

-What does mental illness look like to traditional healers?

- How do they treat someone who has been bewitched?

- Who would want to bewitch a child?

- How does a traditional healer neutralise this?

- How can the traditional healer tell the difference between bewitchment and malaria?

- Why do people bewitch each other?

- How do you detect who is a con-man (with regard to traditional healers)?

-What do they do with con-men?

- What treatments are used for 'worrying' patients?

- How do they treat mental illness? What are the main

treatments for mental illness?

- Can one person transfer a bad demon to another person, and if so how?

- How do they make a demon go into a lake rather than into another person?

-What causes depression?

- Does AIDS cause mental illness?

- What causes mental illness?

- How can you treat mental illness if you don't know where it comes from?

were invited by the district cultural officer to attend a 1-day workshop at Chulaimbo healthcare centre.

\section{Data collection}

The THPs were brought together into the Chulaimbo rural health training centre (RHTC) and divided into two groups, who each met for 2 hours as a focus group. The focus groups were led in Luo, the local language, and moderated by the lead author, Dr Okonji, a consultant psychiatrist originally from the district, and Mr Ayuyo, a public health nurse working in Chulaimbo RHTC.

A range of issues pertaining to the nature, aetiology, symptoms and classification of mental illness and treatment approaches were addressed in the focus groups. The broad areas covered are listed in Box 1. Issues discussed in the focus groups were meticulously documented verbatim and merged for the subsequent analysis.

\section{Data analysis}

Documentation of the discussions in the focus group was read and coded by the researchers using a thematic approach to ascertain the views of THPs pertaining to the nature, aetiology, symptoms and classification of mental illness and treatment approaches, and any other emergent issues.

\section{Results}

The identified themes are described below.

\section{Illnesses treated by THPs}

When asked what illnesses they treated, the THPs replied, in their own words, that they treated typhoid, tuberculosis, cancer, diabetes, infertility and mental illness.

\section{The consultation process}

When asked about the process of THP-client consultation, the following thematic clusters emerged: welcoming the patient, history taking from the patient, enquiry about treatment received from the hospital, collateral history from those who bring the patient, provision of treatment, continuing observation and assessment, and monitoring of efficacy. THPs reported having a special way of looking at patients to discriminate between bewitchment and malaria.

\section{Symptoms}

When asked how the THPs recognised mental illness, the following thematic clusters emerged:

O behavioural abnormalities - agitation, hostility and violence

O affective symptoms - sadness, moodiness, anxiety and fear of dying

O somatic symptoms - unable to stand, malaise, tiredness, weakness, palpitations, headaches and fever

o abnormalities of talk - talking loudly, unable to talk and mutism

oncertainty about what is wrong on part of the person who brings them.

\section{Aetiology}

When asked about their opinion of the causes of mental illness, the following thematic clusters emerged:

O different mental illnesses have different causes

O stressful life events - bereavement, household problems, relationship problems, fear of dying, accidents, injuries, poverty and insufficient food

heredity

alcohol misuse

ancestral influence and supernatural possession - devils, demons and evil (demons occur if a child is not given an inhaler to sneeze properly at birth, if insects are not removed from the head, or if one of the parents does 'bad things')

o people bewitch each other because of quarrels, disputes, pride and showing off

anxiety is caused by rapid beating of the heart, severe headaches, blood not circulating properly and a weak brain.

\section{Treatments}

When asked about the kinds of treatment which THPs would use for mental illness, the following thematic clusters emerged:

O treatment depends upon the type of mental illness

O different methods of treatment are used by different THPs

all drugs, including herbs, have side-effects.

The types of treatments used included:

o herbs prepared in different ways (boiled, ground, soaked in water, mixed with water and drunk, shaken into a bottle and herbal steam baths) and used for smelling and sniffing (to induce sneezing), spreading or spraying on the body and oral intake

burning branches

o scratching of the abdomen and using animal horns to suck out the 'contents' of the abdomen

cutting arms and legs and applying herbs

talking to patients about stressful life events, counselling and advising patients to dig the shamba (farm) and to conduct business

O spiritual therapy, including prayer by THPs, advising patients to pray, and removal of demons, devils and spirits near a lake and by singing. 
There were regular referrals from more generalist THPs to THPs who specialised in certain types of mental illness.

\section{Collaboration}

The following thematic clusters pertaining to collaboration with modern medical services emerged:

O THPs certainly felt that they can treat illnesses that doctors and nurses cannot treat, including bewitchment and possession by demons, devils and spirits

O THPs requested a base in primary care centres to facilitate such treatment

O THPs normally send patients who they consider have malaria, tuberculosis, meningitis and AIDS to the hospital

O THPs felt they cannot effectively treat chronic psychosis and ask families to take such patients to the hospital

O THPs requested collaboration with modern medical services to give long-term support to patients with chronic psychosis.

\section{Discussion}

This study has significant methodological limitations, including its descriptive design, the relatively large size of the focus groups and the restriction of the study to one region of Kenya. However, the thematic clusters of symptoms of mental illness, aetiology and treatment are similar to those observed in Nigeria (Olugbile et al, 2007) and South Africa (Zabow, 2007) and elsewhere in Kenya (Ndetei, 2007). Moreover, many of the symptoms and aetiological features, including recognition of genetic, social, psychological and environmental factors, were similar to those observed in Western psychiatry. Although the THPs were a heterogeneous group with heterogeneous practices, in keeping with previous observations (Zabow, 2007), this study found that their overall stated approach to assessing and treating people with mental illness included history taking, enquiry about treatment received from the hospital, collateral history, provision of treatment, continuing observation and assessment, and monitoring of efficacy.

The THPs reported using several different treatment strategies, including psychotherapy in the form of talking to the patients about stressful life events, counselling and giving practical advice to patients to undertake certain tasks. The practice of relatively sophisticated interpersonal psychotherapy, family therapy and behavioural treatments by Kenyan THPs has been anecdotally observed elsewhere (Ndetei, 2007).

The THPs were unanimous in their expressed desire for collaboration with formal health services. They recognised some of their limitations in treating certain illnesses, including tuberculosis, meningitis, malaria and AIDS, for which they prefer to refer patients to hospital. They also believed that they can treat patients whom doctors and nurses are unable to treat, including those who are bewitched and possessed by demons, devils and evil spirits, and they requested a base in primary care to assist in the treatment of such patients.

There has been encouragement for low- and middleincome countries to develop their own national policies in relation to traditional health practice, national regulatory bodies and professional organisations to address competency, regulation and quality assurance for THPs, similar to those for healthcare professionals (World Health Organization, 2002). This is being implemented in a number of countries, including South Africa (Zabow, 2007), Nigeria (Olugbile et al, 2007) and Tanzania (Ngoma et al, 2003). Further research and liaison are important to reduce potentially harmful practices, to improve the possibility of early diagnosis and effective treatments for people attending THPs, and to strengthen continuity of care for vulnerable clients.

\section{Acknowledgements}

We are grateful to: Mr C. Kigani, Clinical Officer in Charge, Chulaimbo Rural Health Training Centre; the District Cultural Officer; and the traditional health practitioners and birth attendants who kindly gave their time to the study.

\section{References}

Dhapdale, M., Cooper, G. \& Cartwright-Taylor, L. (1989) Prevalence and presentation of depressive illness in a primary health care setting in Kenya. American Journal of Psychiatry, 146, 659-661.

Dhapdale, M. \& Ellison, R. H. (1983) The frequency of mental disorders in the out-patients of two Nyanza hospitals. Central African Journal of Medicine, 29, 29-32.

Katz, S. H. \& Kimani, V. N. (1982) Why patients go to traditional healers East African Medical Journal, 59, 170-174.

Muluka, E. A. P. \& Dhapdale, M. (1986) District focus: management of psychiatric disorders in general practice. East African Medical Journal, 63, 562-565.

Ndetei, D. M. (2007) Traditional healers in East Africa. International Psychiatry, 4, 85-86.

Ndetei, D. M. \& Muhangi, J. (1979) The prevalence and clinical presentation of psychiatric illness in a rural setting in Kenya. British Journal of Psychiatry, 135, 269-272.

Ngoma, M. C., Prince, M. \& Mann, A. (2003) Common mental disorders among those attending primary care health clinics and traditional healers in urban Tanzania. British Journal of Psychiatry, 183, 349-355.

Odejide, A. O., Olatawaru, M. O., Sanda, A. O., et al (1978) Traditional healers and mental illness in the city of Ibadan. Journal of Black Studies, 4, 195-205.

Olugbile, O., Zachariah, N. P. \& Isichei, B. (2007) Nosology and modalities for deciding on the management of patients with psychiatric illness among traditional healers in Lagos, Nigeria. International Psychiatry, $4,83-84$

Otsyula, W. (1973) Native and Western healing: the dilemma of East African psychiatry. Journal of Nervous and Mental Disease, 156, 297-299.

Sebit, M. B. (1996) Prevalence of psychiatric disorders in general practice in Nairobi. East African Medical Journal, 73, 631-633.

World Health Organization (2002) WHO Traditional Medicine Strategy 2002-2005. WHO

Zabow, T. (2007) Traditional healers and mental health in South Africa International Psychiatry, 4, 81-83.

International Psychiatry is committed to the promotion of high-quality research and reporting from and about low- and middleincome countries, and cross-cultural and cross-national collaboration in the advancement of clinical science, education and advocacy in psychiatry and mental health. The original papers section of International Psychiatry is dedicated to the publication of high-quality original research and systematic reviews. Papers will be peer reviewed quickly, for publication in the next available issue of the journal, although not all papers will be accepted for publication. Articles should be no more than 1500 words, with a maximum of two tables or figures and 12 key references. Wherever possible, our expert panel of assessors will help authors to improve their papers to maximise their impact when published. Please send your submissions to ip@rcpsych.ac.uk. 